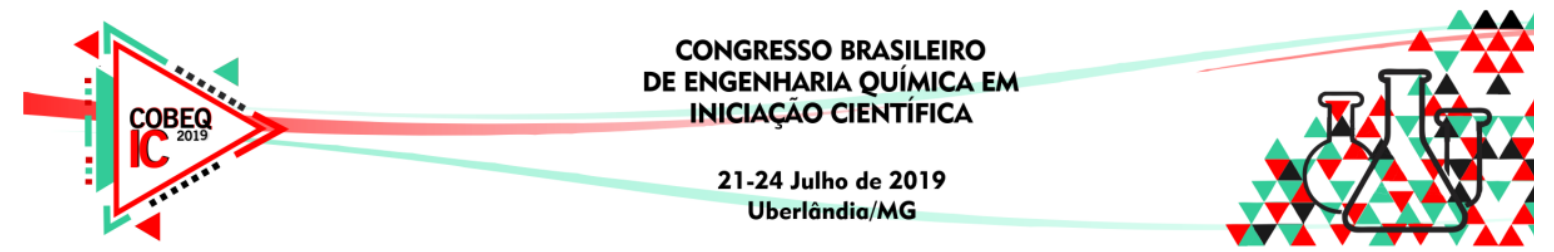

\title{
PREPARO DE FILMES DE POLIESTIRENO PARA FINS DE IMOBILIZAÇÃO DE DIÓXIDO DE TITÂNIO UTILIZADO EM FOTOCATÁLISE HETEROGÊNEA
}

\author{
L.D. SILVEIRA, J.E. SAVOIA, R.G. MARQUES, L.S. MORAES \\ Universidade Tecnológica Federal do Paraná, Câmpus Apucarana \\ E-mail para contato: lucas.damiao@hotmail.com
}

\begin{abstract}
RESUMO - Nos últimos anos a fotocatálise heterogênea, empregando como catalisador o dióxido de titânio $\left(\mathrm{TiO}_{2}\right)$, tem demostrado excelentes resultados na degradação de contaminantes do tipo recalcitrantes. Entretanto, é desejável imobilizar o catalisador em um suporte para facilitar a remoção do primeiro do efluente tratado. Uma solução seria o uso de filmes poliméricos, como os de poliestireno, empregando para tanto material advindo do reciclo de isopor (poliestireno expandido) para imobilizar o $\mathrm{TiO}_{2}$, tema desse estudo.
\end{abstract}

\section{INTRODUÇÃO}

Uma enorme quantidade de poluentes químicos, advindos do descarte incorreto de efluentes das mais diversas atividades, tem preocupado a comunidade científica, pois a contaminação do meio ambiente por esses efluentes pode acarretar perdas sem precedentes, sendo apontada como um dos maiores problemas da sociedade moderna. Com a conscientização da sociedade e consequente pressão junto aos órgãos competentes, novas medidas mais rígidas têm sido implementadas. Entretanto ainda há muito espaço para melhoria: segundo dados da CETESB, a geração de resíduos perigosos passa de 820.000 toneladas por ano (Cervantes et al., 2009).

Segundo Dezotti (2008), os efluentes denominados recalcitrantes ou persistentes possuem grande potencial poluidor, e devido a sua alta estabilidade química e fotoquímica, tratamentos primários ou biológicos são incapazes de remover tais contaminantes do meio pluvial. Existem alguns tratamentos mais eficientes que visam degradar esses contaminantes transformando-os em substâncias mais estáveis e inertes, como dióxido de carbono e água. Dentre esses destacamse os processos oxidativos avançados, POAs (Brito e Silva, 2012).

Os POAs são tecnologias alternativas que envolvem oxidantes fortes ou catalisadores (na exposição ou não de radiação), para gerar radicais hidroxila altamente reativos, a fim de minerar as substâncias orgânicas presentes nos efluentes (Cordeiro et al., 2004).

A fotocatálise heterogênea é um processo oxidativo avançando que, segundo Cruz et al. (2010), nos últimos anos tem demostrado excelentes resultados quando se trata de degradar poluentes ambientais. Uma das vantagens desse processo é que não há limitações de transferência de massa, além de poder ser operado em condições ambientes, aproveitando-se da radiação solar para fornecer energia e iniciar o procedimento fotocatalítico. À medida que a 


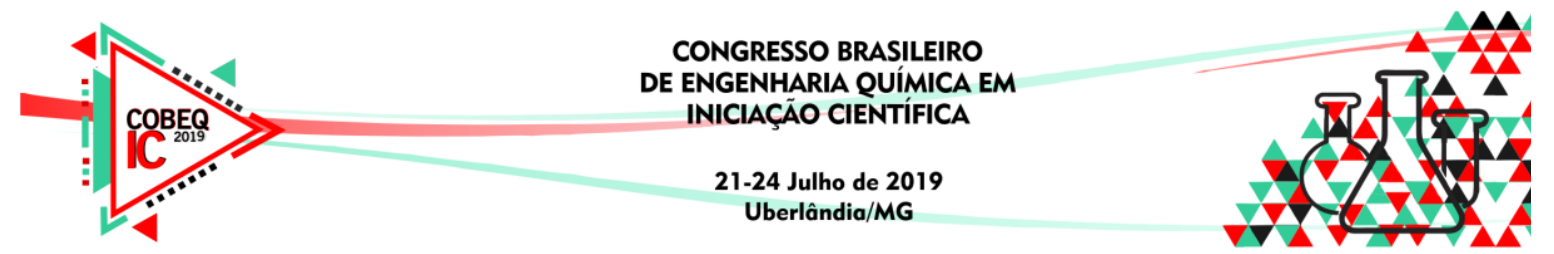

energia fornecida se iguala ao "band gap", o radical hidroxila (HO·) é formado a partir lacuna fotogerada com moléculas de água ou íons hidroxilas que estavam superficialmente adsorvidos no catalisador (Hoffmann et al., 1995). O catalisador mais utilizado em fotocatálise heterogênea é o dióxido de titânio $\left(\mathrm{TiO}_{2}\right)$, substância quimicamente estável, atóxica e fotoestável, características que a tornam ideal para aplicações em processos dessa natureza, além de ser um produto de custo relativamente baixo - o $\mathrm{TiO}_{2}$ é o pigmento branco mais utilizado no mundo (Saleiro et al., 2010).

$\mathrm{Na}$ aplicação, o catalisador em pó pode ser utilizado de diversas maneiras: disperso na solução aquosa, em um leito fluidizado ou imobilizado em um suporte adequado. Contudo, existe a preferência da aplicação em um suporte, na tentativa de minimizar os gastos com processos de separação, uma vez que o catalisador é um pó fino de difícil separação após a etapa de tratamento do efluente. O suporte escolhido deve apresentar como características: boa estabilidade mecânica, ser transparente à luz UV, possuir forte ligação físico-química entre as moléculas do catalisador a ser suportado, não afetar negativamente a fotocatálise, ser facilmente removido do meio líquido. (Saleiro et al., 2010).

Filmes de poliestireno podem ser uma boa opção para imobilizar o dióxido de titânio, tendo em vista que possuem grande parte das propriedades necessárias descritas acima. Além disso, os filmes podem ser produzidos a baixo custo através da reciclagem do poliestireno expandido (comercialmente conhecido como isopor), que ainda é pouco explorada.

\section{OBJETIVOS}

Produzir filmes de poliestireno (aproveitando a reciclagem do poliestireno expandido), capazes de imobilizar o dióxido de titânio, a fim de ser usado em catálise heterogênea, sem afetar negativamente a reação fotocatalítica.

\section{METODOLOGIA}

\subsection{Preparo de filmes}

Os filmes foram preparados seguindo o fluxograma apresentado na Figura 1. Em um ambiente controlado (capela) preparou-se duas soluções com diferentes concentrações em massa de poliestireno expandido (PS), sendo a primeira com $20 \% \mathrm{~m} / \mathrm{m}$ e a segunda $30 \% \mathrm{~m} / \mathrm{m}$, utilizando como solvente o acetato de etila. Após o preparo, espalhou-se as soluções em placas de Petri $(\phi=90 \mathrm{~mm})$ até formar uma fina película, em seguida dispersou-se de maneira uniforme uma massa conhecida de dióxido de titânio P25 (Evonik, 89\% anatase e 11\% rutile) - 0,25 g ou $0,5 \mathrm{~g}$ em sua superfície. Para formação dos filmes, as placas foram mantidas em uma superfície nivelada até total evaporação do solvente. Para fins de comparação, foram produzidos filmes sem catalisador disperso e também foram realizados dois tipos de evaporação, uma mais rápida com os filmes expostos diretamente a atmosfera, e uma mais lenta, com a placa parcialmente coberta. 


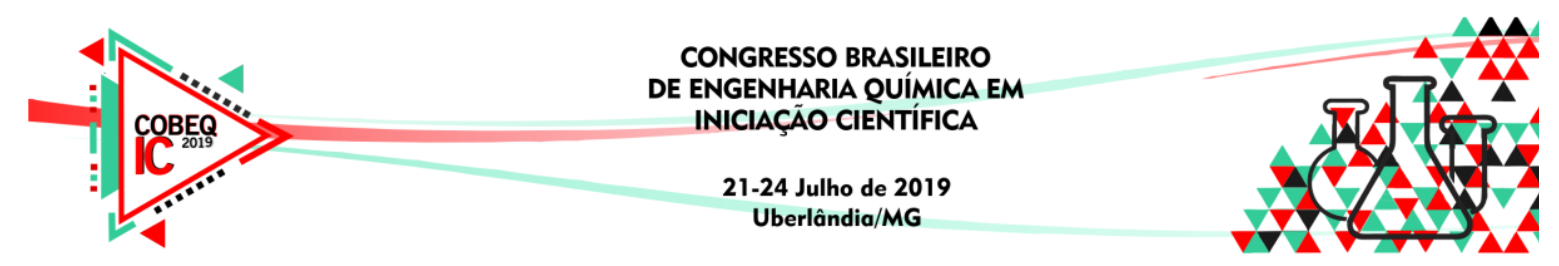

Figura 1 - Fluxograma das etapas de preparo de filmes.

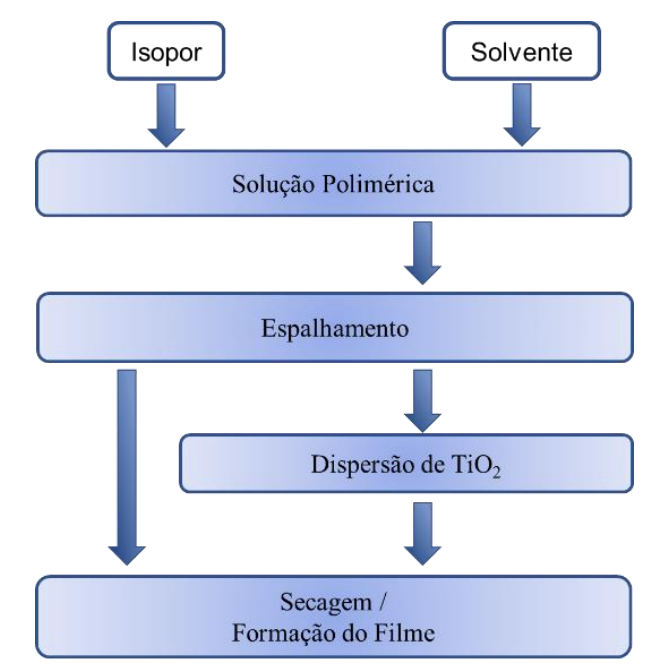

\subsection{Testes de adsorção}

Os testes de adsorção foram realizados com base em solução padrão aquosa de corante (azul de metileno), $10 \mathrm{mgL}^{-1}$, empregando filmes com e sem catalisador, com a finalidade de garantir o equilíbrio da adsorção. Após 60 minutos sobre agitação, com auxílio de um espectrofotômetro, determinou-se o espectro de absorção UV-Vis.

\subsection{Testes fotocatalíticos}

Os testes fotocatalíticos foram geridos de maneira semelhante ao teste de adsorção: nesse caso, as amostras foram submetidas à lâmpada germicida UV C (18 W), sendo avaliada a absorbância após diferentes frações de tempo de exposição. Além dos testes fotocatalíticos, também foi adicionada uma amostra de solução sem adição de catalisador para testes de fotólise. Em ambos os casos, o tempo de exposição máximo foi de 120 minutos.

\section{RESULTADOS E DISCUSSÕES}

\subsection{Produção dos filmes}

A tabela 1 demonstra as imagens dos filmes produzidos, em diferentes condições. Em se tratando apenas dos filmes sem adição de catalisador, podemos observar que aqueles produzidos a partir de evaporação lenta apresentam transparência maior quando comparados aos produzidos através de evaporação rápida. Isso se deve ao fato de que ao tampar os filmes na fase de evaporação, a atmosfera fica saturada de solvente, o que retarda a evaporação do mesmo e faz com que a aproximação entre as moléculas do polímero seja mais efetiva, permitindo a formação de um filme denso. Com a adição de catalisador, apenas nos filmes preparados pelo método de evaporação rápida o catalisador permanece na superfície no filme, já que, na evaporação lenta, ocorre migração das partículas de catalisador para as camadas internas do filme tornando a superfície do catalisador indisponível para adsorção da molécula do corante na etapa fotocatalítica. 


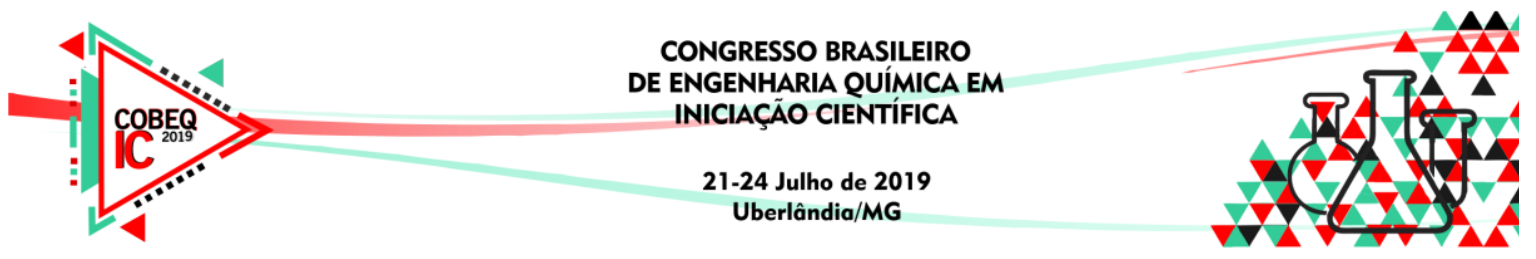

Tabela 1- Produção de filmes por meio da técnica de evaporação de solvente. Filmes produzidos na ausência ou presença de catalisador $\mathrm{TiO}_{2}$, por evaporação rápida ou lenta e diferentes concentrações de isopor na solução polimérica

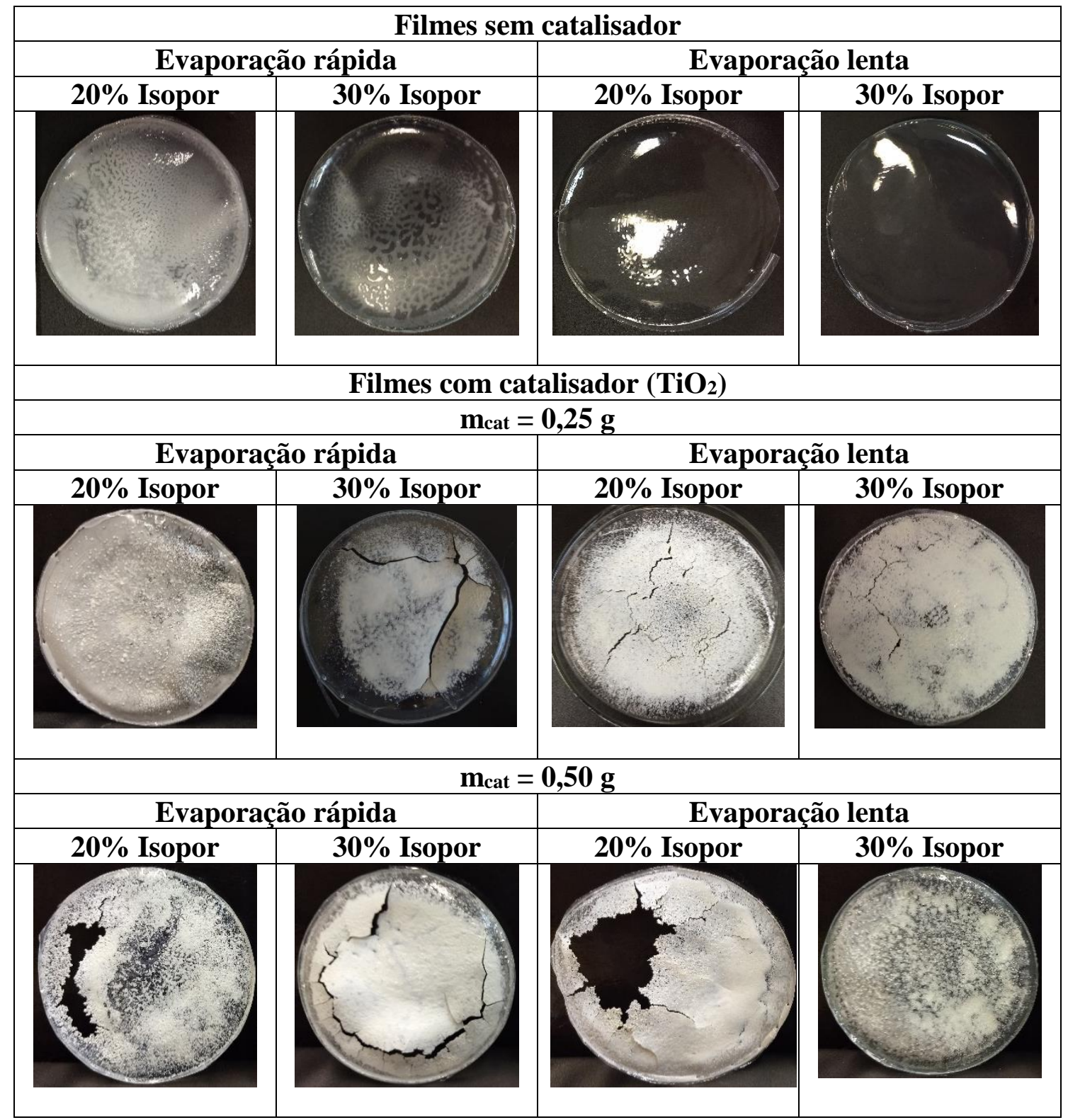

A quantidade de catalisador também afetou a formação dos filmes: o aumento dessa quantidade dificulta a formação dos filmes, tornando-os mais quebradiços. Em alguns casos, não ocorre a formação do filme, como pode-se verificar na Figura 1, especialmente para a condição de maior massa de catalisador $(0,50 \mathrm{~g})$ e menor concentração de polímero $(20 \% \mathrm{~m} / \mathrm{m})$. O maior teor de poliestireno na solução polimérica também é um fator determinante para os filmes: aqueles produzidos a partir de solução contendo 30\% de PS em solvente apresentaram maior resistência mecânica. 

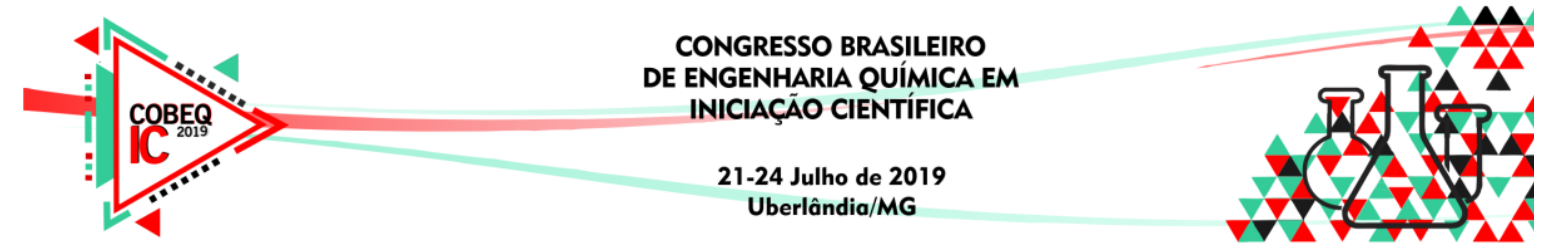

\subsection{Teste de adsorção}

Com os filmes produzidos na etapa anterior, foram realizados testes de adsorção, conforme metodologia apresentada. A partir dados obtidos através do espectro de absorção UVVis foram plotados diversos gráficos de absorbância em função do comprimento de onda (Figura 2). Verifica-se que houve mudança significativa na absorbância para a amostra contendo apenas o catalisador disperso no meio, o que significa que o corante foi adsorvido pelo catalisador. Para as demais amostras, não houve mudanças significativas.

Figura 2 - Variação da absorbância em função do comprimento de onda $(\lambda)$ para os testes de adsorção de filmes de poliestireno com e sem catalisador.

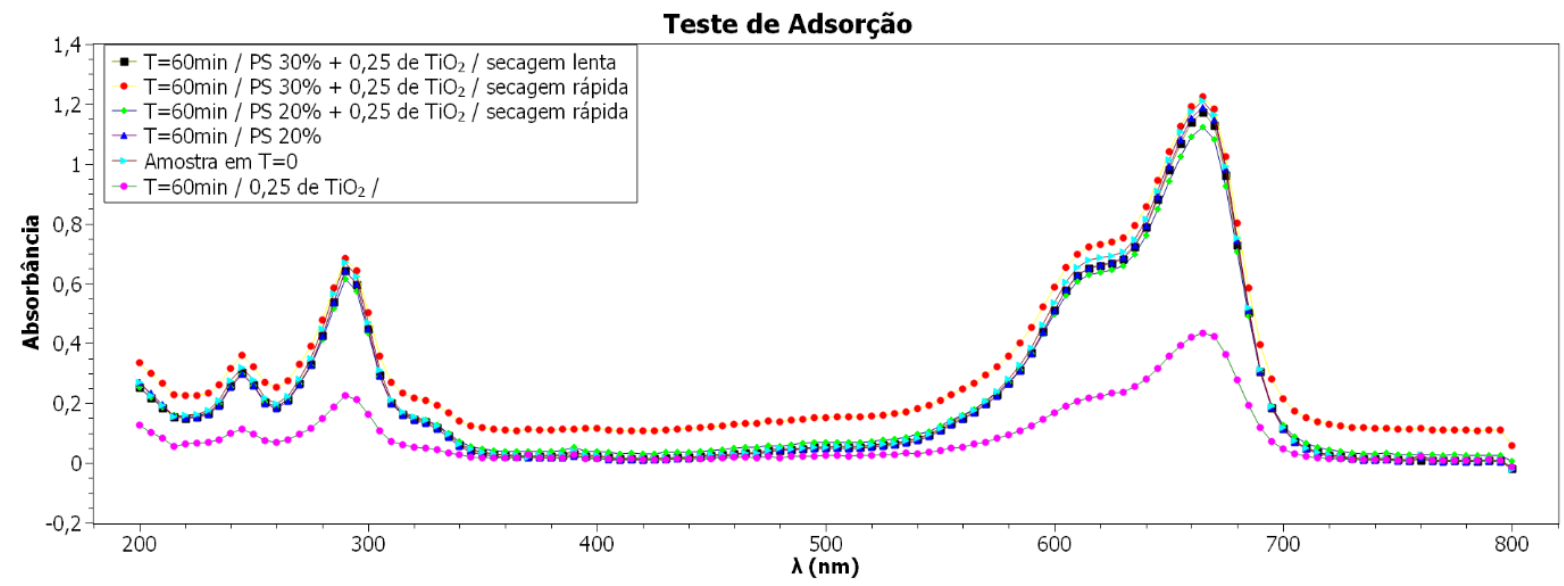

\subsection{Teste fotocatalítico}

Após o teste de adsorção, foram realizados os testes fotocatalíticos, com o objetivo de verificar a degradação do corante na presença de catalisador $\mathrm{TiO}_{2}$ e UV. Os resultados são apresentados nos gráficos contidos na Figura 3, e demonstram a variação da absorbância com o comprimento de onda após 120 minutos de exposição à luz UV.

Figura 3 - Variação da absorbância com o comprimento de onda $(\lambda)$ para os ensaios fotocatalíticos após 120 minutos de reação

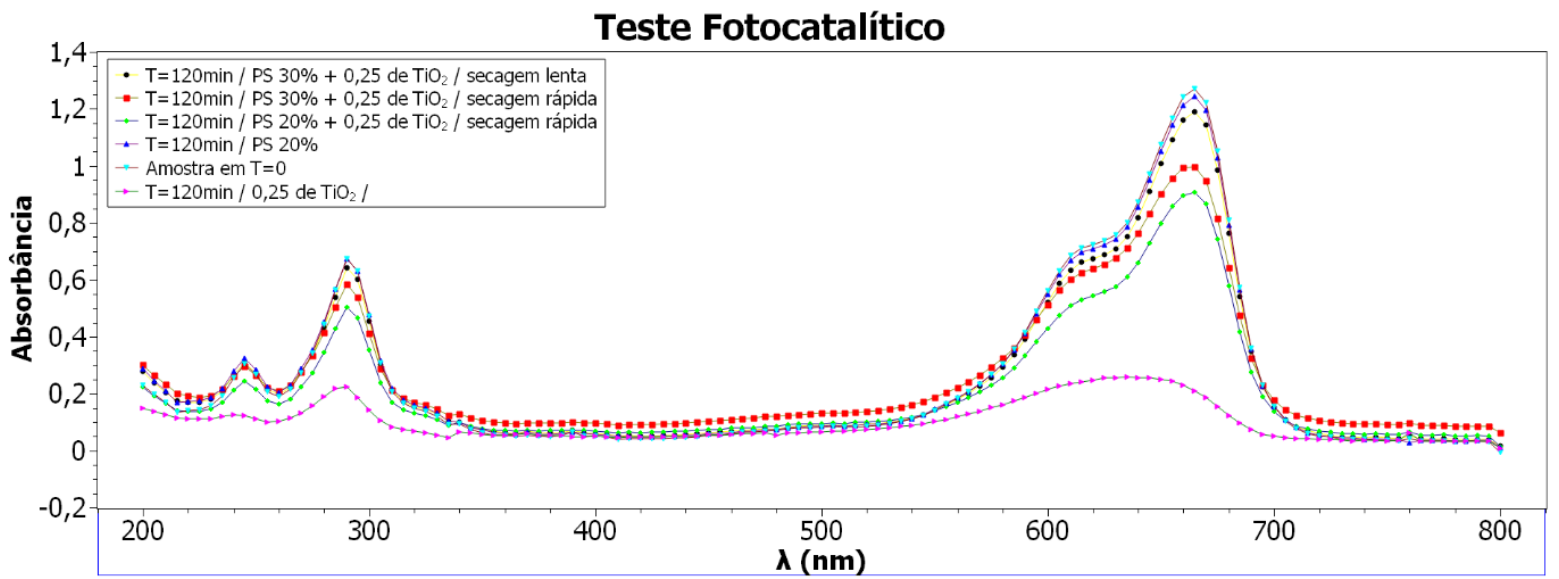




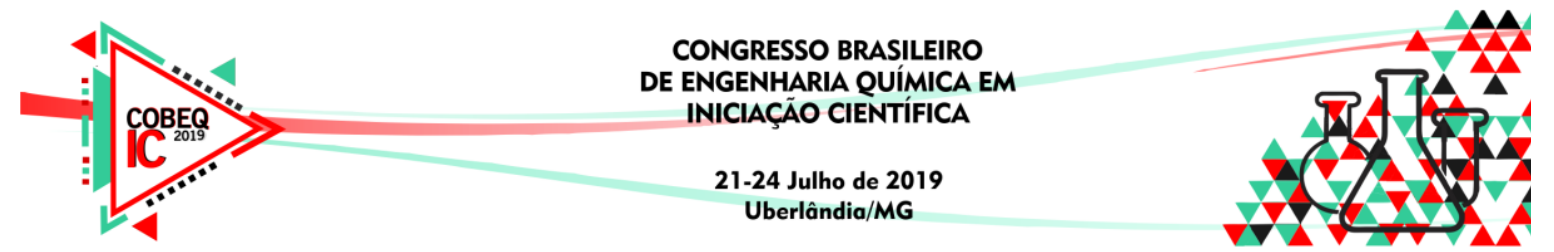

Verifica-se, em comparação à amostra inicial $(\mathrm{T}=0)$, que todas as demais apresentaram diminuição de pico de absorbância, em maior ou menor intensidade. Esse é um forte indicativo de que o corante está sendo degradado; porém as amostras com o catalisador imobilizado não alcançaram o mesmo nível de redução que a amostra com catalisador disperso. Esse resultado, já esperado, deve-se ao fato de que a imobilização do catalisador no suporte provoca diminuição na área superficial do catalisador. Ainda assim, pode-se perceber que dentre as amostras com catalisador imobilizado em filmes sujeitos à evaporação rápida, houve degradação do corante, mostrando que a técnica tem potencial para aplicação em fotocatálise heterogênea.

\section{CONCLUSÃO}

Os filmes de poliestireno demostram ter boas características podendo ser aproveitados como suportes para imobilização de fotocatalisadores, pois facilitam a remoção do catalisador do efluente tratado, sem afetar negativamente o processo. Entretanto, nos testes realizados, a quantidade de catalisador em sua superfície ainda não é suficiente para obter resultados proporcionais ao procedimento que utiliza o catalisador disperso, o que demonstra que há espaço para melhorias em relação à técnica de preparo dos filmes.

\section{REFERÊNCIAS}

BRITO, N. N de; SILVA, V. B. M. Processo oxidativo avançado e sua aplicação ambiental. Revista eletrônica de engenharia civil. V. 1, p. 36-37, 2012.

CERVANTES, T. N. M.; ZAIA, D. A. M. e SANTANA, de H. Estudo da fotocatálise heterogênea sobre ti/tio2 na descoloração de corantes sintéticos. Quim. Nova, Vol. 32, p. 2423-2428, 2009.

CORDEIRO, A. C. de S.; LEITE, S. G. F. e DEZOTTI, M. Inativação por oxidação fotocatalítica de Escherichia coli E Pseudomonas. Quim. Nova, Vol. 27, p. 689-694, 2004.

CRUZ, L. H. da; HENNING, F. G.; SANTOS, A. B. dos. e PERALTA-ZAMORA, P. Degradação fotocatalítica de sulfametoxazol, trimetoprima e diclofenaco em solução aquosa. Quim. Nova, Vol. 33, p. 1270-1274, 2010.

DEZOTTI, M., Processos e técnicas para o controle ambiental de efluentes líquidos. Rio de Janeiro, E-papers, 2008.

HOFFMANN, M. R.; MARTIN, S. C.; CHOI, W.; BAHNEMANN, D. W.; Environmental Applications of Semiconductor Photocatalysis, Chemical Reviews, p. 95, 69, 1995.

SALEIRO, G. T.; CARDOSO, S. L.; TOLEDO, R.; HOLANDA, J. N. F. Avaliação das fases cristalinas de dióxido de titânio suportado em cerâmica vermelha, Cerâmica 56, 162-167, 2010. 